\title{
Broadband Vertically/Horizontally Dual-Polarized Antenna for Base Stations
}

\author{
YueHui Cui, XiaoNa Gao, and RongLin Li \\ School of Electronic and Information Engineering, South China University of Technology, Guangzhou 510641, China \\ Correspondence should be addressed to YueHui Cui; eeyhcui@scut.edu.cn
}

Received 7 September 2016; Revised 18 January 2017; Accepted 31 January 2017; Published 6 March 2017

Academic Editor: Ana Alejos

Copyright (C) 2017 YueHui Cui et al. This is an open access article distributed under the Creative Commons Attribution License, which permits unrestricted use, distribution, and reproduction in any medium, provided the original work is properly cited.

\begin{abstract}
A broadband vertically/horizontally $(\mathrm{V} / \mathrm{H})$ dual-polarized antenna is proposed for mobile communication base stations. The antenna consists of two perpendicularly placed broadband planar antenna elements. By shaping the reflector for $\mathrm{V} / \mathrm{H}$ dual-polarized antenna, a half-power beam width of $65 \pm 8^{\circ}$ is achieved for both vertical and horizontal polarization. The V/H dual-polarized antenna has a bandwidth of $48 \%(1.7-2.75 \mathrm{GHz})$ for return loss $>15 \mathrm{~dB}$, an isolation of $30 \mathrm{~dB}$, and an antenna gain of $9 \mathrm{dBi}$. An 8-element $\mathrm{V} / \mathrm{H}$ dual-polarized antenna array is developed, which achieves a bandwidth of $45 \%(1.7-2.7 \mathrm{GHz})$ and an antenna gain of $16 \mathrm{dBi}$, suitable for GSM/UMTS/LTE base stations.
\end{abstract}

\section{Introduction}

Dual-polarized antennas are widely used in mobile communication base stations to improve the system performance by utilizing polarization diversity [1]. Vertically/horizontally $(\mathrm{V} / \mathrm{H})$ dual-polarized antennas are suitable for base stations in suburban and rural areas because the vertical polarization is dominant in these environments $[2,3]$. And normally a $\mathrm{V} / \mathrm{H}$ array has a higher isolation than $\mathrm{a} \pm 45^{\circ}$ array. In recent years, lots of dual-polarized antennas have been developed for base stations [4-20]. Most of dual-polarized antennas consist of a patch [4-13] or two crossed dipoles [14-19]. It is well known that patch antennas and dipole antennas usually have different beam widths in the E-plane and H-plane. For example, the half-power beam widths (HPWBs) for the $\mathrm{V} / \mathrm{H}$ dual-polarized antenna in [18] are about $60^{\circ}$ in the E-plane and $70^{\circ}$ in the $\mathrm{H}$-plane. Therefore it is quite difficult to achieve the same beamwidth (e.g., $\sim 65^{\circ}$ ) in the azimuthal plane for both vertical and horizontal polarization, which is usually required for a base station to provide the same coverage for both types of polarization.

In this paper, we present a broadband $\mathrm{V} / \mathrm{H}$ dual-polarized antenna based on the broadband planar antenna element developed in [20]. The $\mathrm{V} / \mathrm{H}$ dual-polarized antenna is composed of two such broadband antenna elements which are placed orthogonally to each other for dual-polarization operation. By shaping the reflector for the $\mathrm{V} / \mathrm{H}$ dual-polarized antenna, a HPBW of $65 \pm 8^{\circ}$ is obtained in the horizontal plane for both vertical and horizontal polarization. The V/H dualpolarized antenna is described in Section 2 and an 8-element antenna array is developed in Section 3.

\section{V/H Dual-Polarized Antenna}

2.1. Antenna Configuration. As illustrated in Figure 1, the $\mathrm{V} / \mathrm{H}$ dual-polarized antenna consists of two perpendicularly placed broadband antenna elements: one is placed for vertical polarization (VP) and the other is placed for horizontal polarization (HP). The broadband antenna element consists of a pair of folded printed dipoles which are coupled to an L-shaped microstrip line [20]. The folded dipoles and the microstrip line are printed on the same substrate, forming a planar antenna element. The horizontal plane (i.e., the $y-z$ plane) is the H-plane for the VP element and the Eplane for the HP element. For a mobile communication base station, the HPBWs in the horizontal plane for both VP and HP elements need to be similar. When the reflector is flat, however, the HPBW for the VP element is about $90 \pm 10^{\circ}$ while being $70 \pm 10^{\circ}$ for the HP element, as demonstrated 


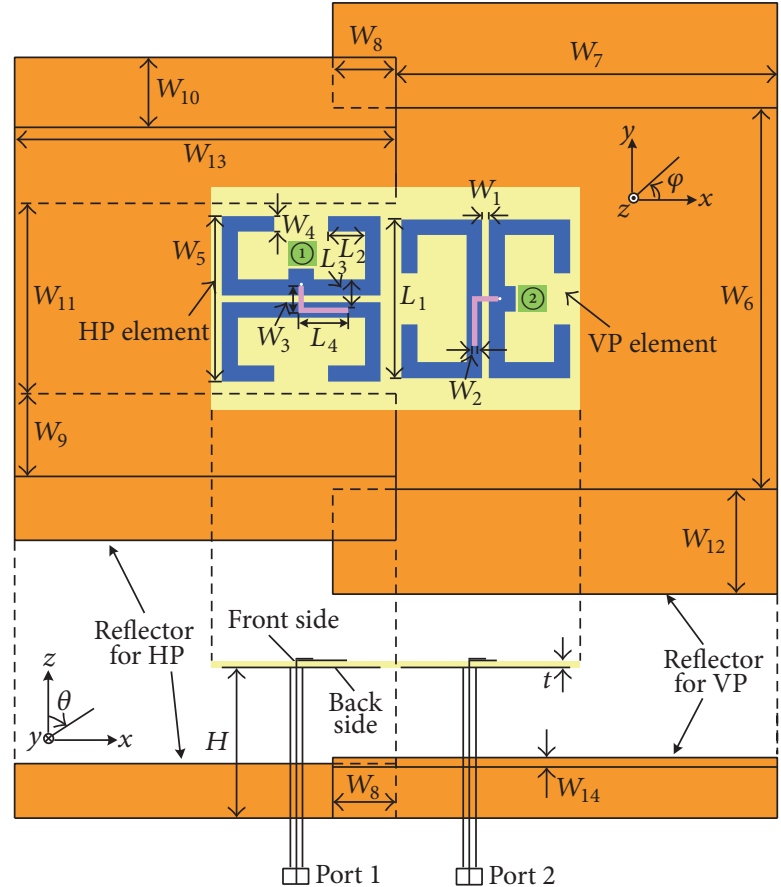

Metal on front side Metal on back side

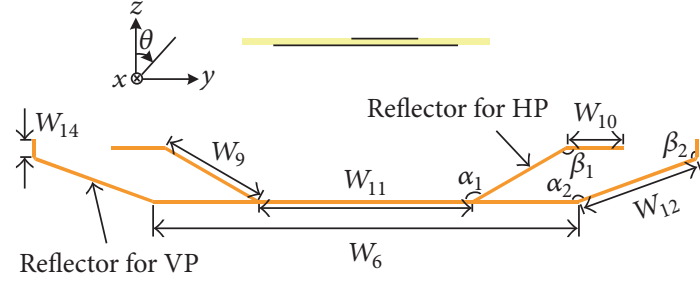

Reflector for VP

FIGURE 1: Configuration of a broadband V/H dual-polarized antenna: (a) top view; (b) side view.

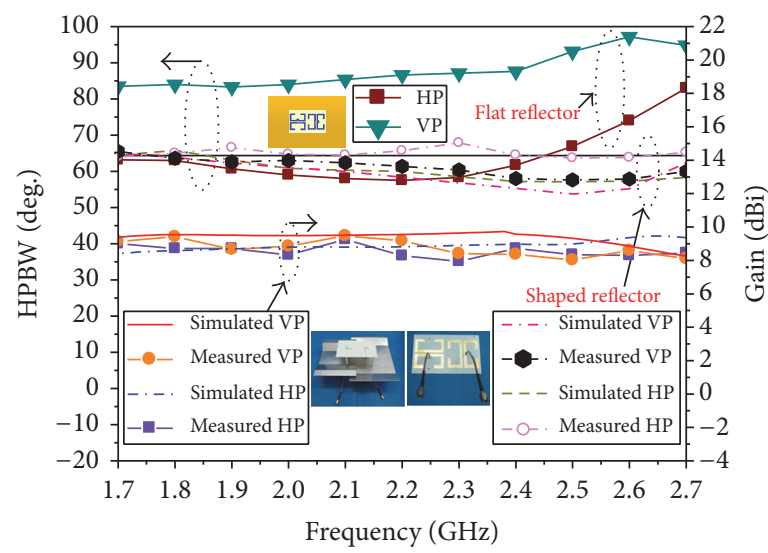

FIGURE 2: HPBWs and gains of the broadband V/H dual-polarized antenna.

in Figure 2, which is not acceptable for base station applications.

The HPBWs for VP and HP in the horizontal plane can be adjusted by shaping the reflector. Since the VP element has a wider HPBW, it needs a wider reflector. It is found by simulation that the total width of the reflector for the VP element is $190 \mathrm{~mm}$ while the total width for the HP element is $160 \mathrm{~mm}$. The shape of the reflector is optimized to obtain a HPBW close to $\sim 65^{\circ}$ for a $120^{\circ}$ sector of a cellular base station. The geometric parameters optimized for the reflector are listed in Table 1 with the geometric parameters for the broadband antenna element.

2.2. Results. The simulated (using Ansoft HFSS v14) and measured HPBWs for the $\mathrm{V} / \mathrm{H}$ dual-polarized antenna are plotted in Figure 2 with an antenna prototype. The simulated HPBWs in the horizontal plane are $65 \pm 8^{\circ}$ for both VP and HP elements while the measured HPBWs are $65 \pm 3^{\circ}$ 

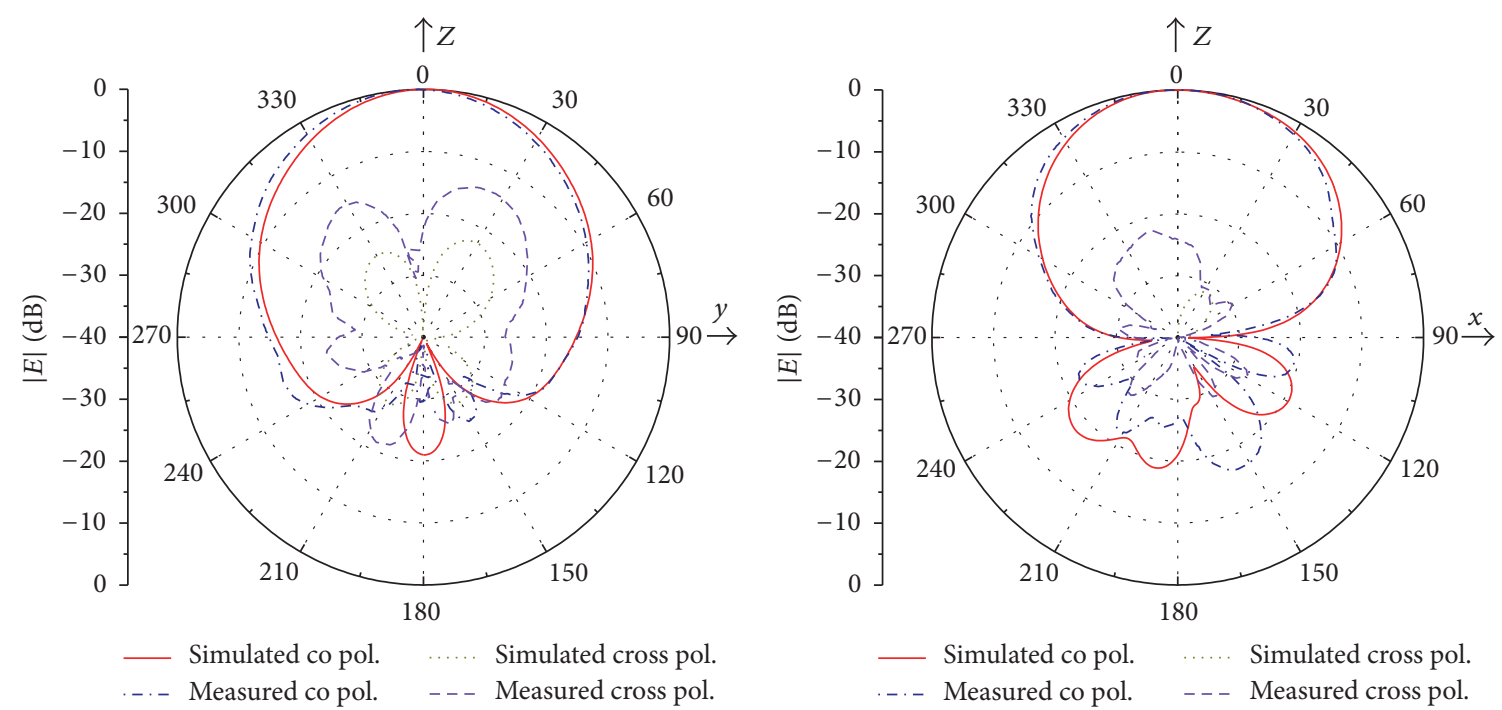

(a)
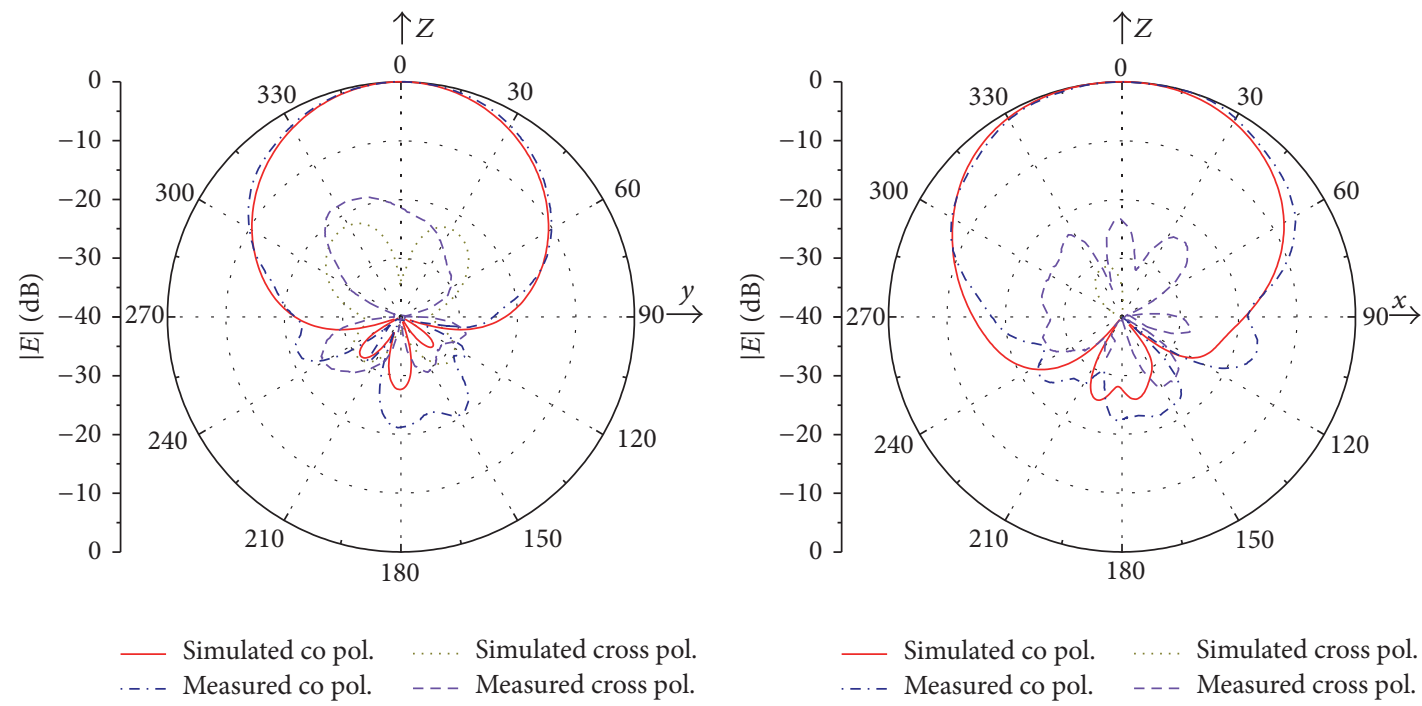

(b)

FIGURE 3: Radiation patterns of the V/H dual-polarized antenna at $2.2 \mathrm{GHz}$ : (a) VP and (b) HP.

for $\mathrm{HP}$ and $65 \pm 10^{\circ}$ for VP over the frequency range 1.72.7 GHz which covers GSM1800 (1710-1880 MHz), GSM1900 (1850-1990 MHz), UMTS (1920-2170 MHz), LTE2300 (2305$2400 \mathrm{MHz})$, and LTE2600 (2500-2690 MHz). The slight discrepancy may be due to measurement errors caused by measurement setup. The radiation patterns simulated and measured for VP and $\mathrm{HP}$ at the center frequency $2.2 \mathrm{GHz}$ are plotted in Figure 3, showing a similar coverage for both VP and HP; the 10-dB beam widths in the $\mathrm{y}-\mathrm{z}$ plane are $120^{\circ}$. (There is no significant difference for the radiation pattern over the frequency range $1.7-2.7 \mathrm{GHz}$.) The antenna gain is about $9 \mathrm{dBi}$ for both VP and HP (also see Figure 2). Simulated and measured $S$ parameters are compared in Figure 4. It can be seen that $|S 11|$ or $|S 22|$ is less than $-15 \mathrm{~dB}$ (or $\mathrm{RL}>$ $15 \mathrm{~dB})$ over a bandwidth of $48 \%(1.7-2.75 \mathrm{GHz})$. The isolation (i.e., $-|S 21|$ in $\mathrm{dB}$ ) between the ports for VP and HP elements is higher than $30 \mathrm{~dB}$. The measured front-to-back ratios compared with the simulation are displayed in Figure 5. The antenna achieves high front-to-back ratios of about $18 \mathrm{~dB}$ for both VP and HP, showing good unidirectional radiation. The antenna efficiency is also depicted in Figure 5, which are higher than $85 \%$.

\section{Dual-Polarized Antenna Array}

For potential applications in mobile communication base stations, an 8-element $\mathrm{V} / \mathrm{H}$ dual-polarized antenna array is developed, as illustrated in Figure 6. The antenna array is composed of eight $\mathrm{V} / \mathrm{H}$ dual-polarized antenna elements with an element spacing of $116 \mathrm{~mm}\left(\sim \lambda_{2.7 \mathrm{GHz}}\right.$, where $\lambda_{2.7 \mathrm{GHz}}$ 


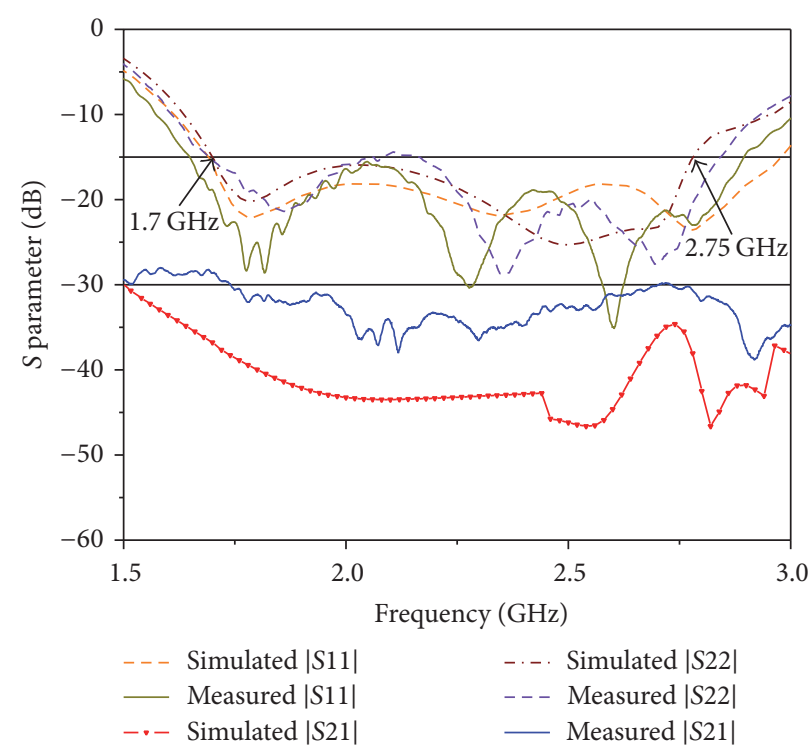

FIGURE 4: $S$ parameters ( $|S 11|,|S 22|$, and $|S 21|)$ simulated and measured for the V/H dual-polarized antenna.

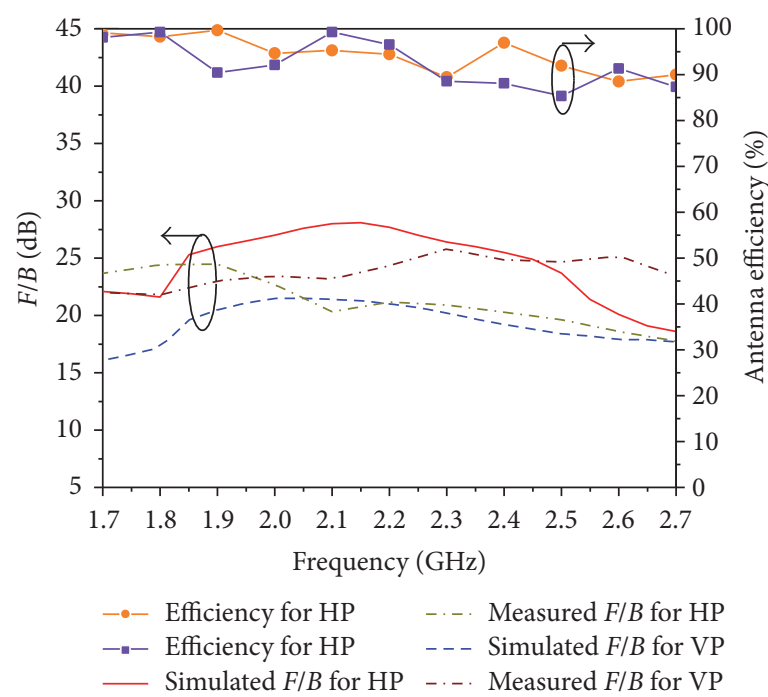

FIGURE 5: Front-to-back ratios and antenna efficiency of the broadband V/H dual-polarized antenna.

is the wavelength in free space at the frequency $2.7 \mathrm{GHz}$ ). The $\mathrm{V} / \mathrm{H}$ dual-polarized antenna array is fed by two eight-way power dividers. Figure 7 shows the measured $S$ parameters for the $\mathrm{V} / \mathrm{H}$ dual-polarized antenna array. The bandwidth for |S11| (or $|S 22|)<-15 \mathrm{~dB}$ is $45 \%(1.7-2.7 \mathrm{GHz})$. The isolation between the ports for VP and HP is about $30 \mathrm{~dB}, \sim 5 \mathrm{~dB}$ higher than that for the $\pm 45^{\circ}$ dual-polarized antenna array proposed in [20]. Simulated and measured HPBWs in the horizontal plane (i.e., the $y-z$ plane) and the elevation plane (i.e., the $x-z$ plane) are plotted in Figure 8. Experimental results show that the 8 -element $\mathrm{V} / \mathrm{H}$ dual-polarized antenna array maintains a HPBW of $65 \pm 8^{\circ}$ in the horizontal plane and a HPBW of $16 \pm 2^{\circ}$ in the elevation plane for both VP and HP over the frequency range $1.7-2.7 \mathrm{GHz}$. The slight inconsistency between the measured results and the simulation may have been caused due to measurement errors during the setup of the experiment. The measured gain is about $16 \mathrm{dBi}$ for both VP and HP, as indicated in Figure 9. The measured gains are slightly lower than the simulated results $(\sim 17.5 \mathrm{dBi})$ due to the loss of the feed network (including the power splitter, coaxial cables, and a SMA connector) which was not taken into account in simulation. The gain variation over the frequency range $1.7-2.7 \mathrm{GHz}$ is less than $1.5 \mathrm{~dB}$. The radiation patterns measured at $1.7 \mathrm{GHz}, 2.2 \mathrm{GHz}$, and $2.7 \mathrm{GHz}$ are compared with simulated results in Figure 10; good agreement is observed. A stable similar coverage over 


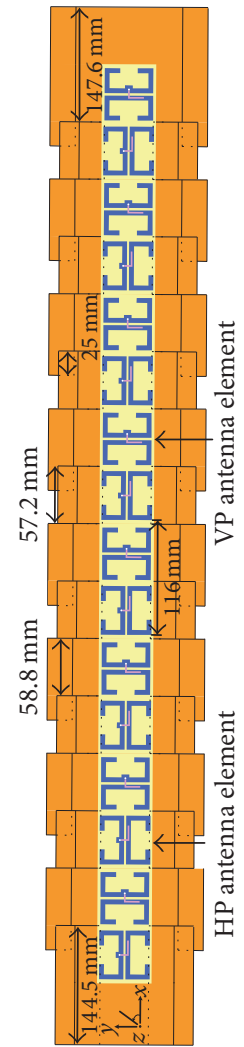

(a)
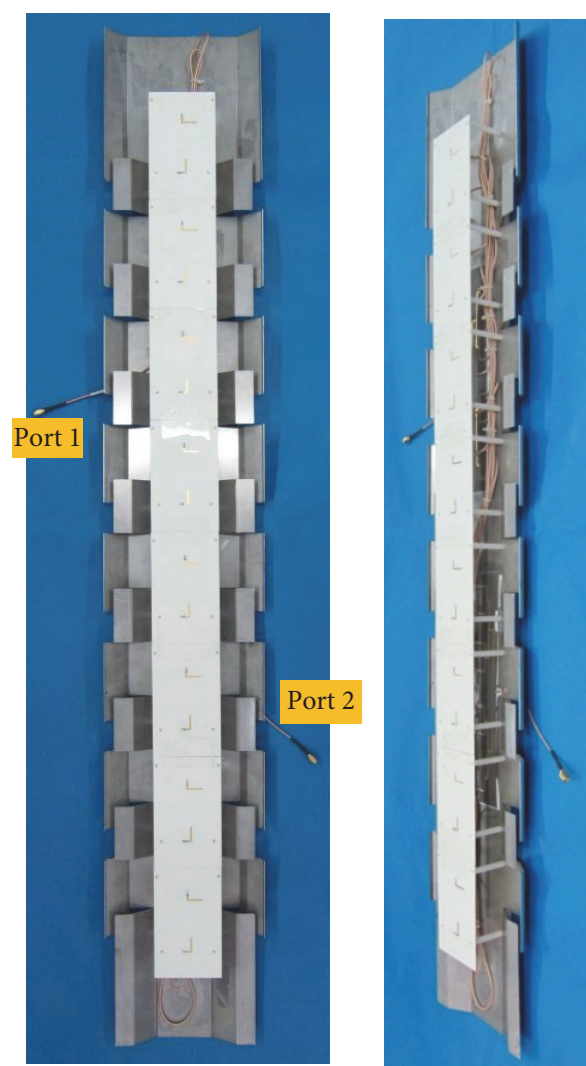

(b)

FigURE 6: A V/H dual-polarized antenna array: (a) geometry of the antenna array; (b) a prototype of the antenna array.

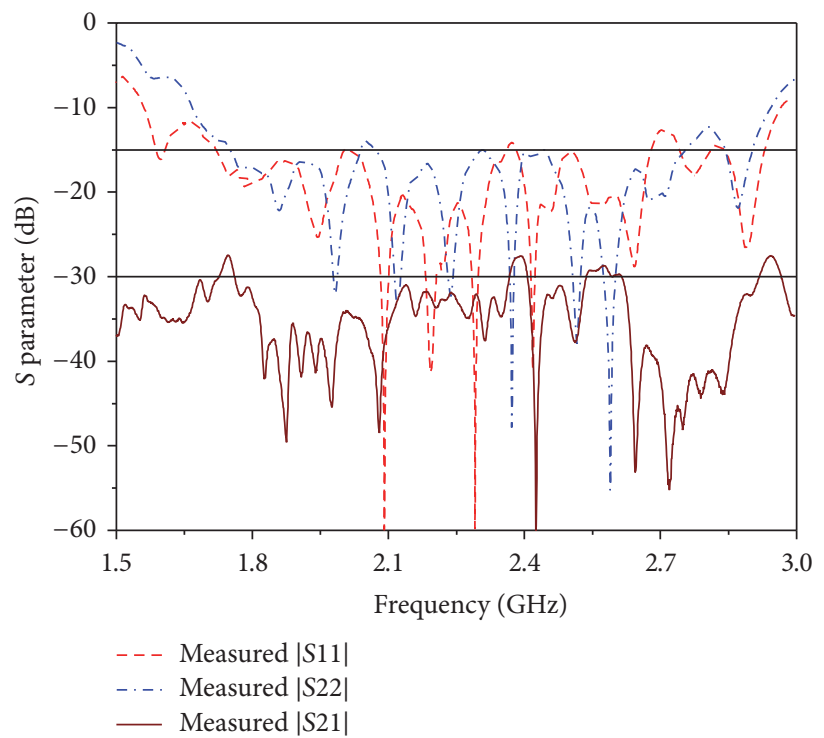

FIGURE 7: Measured $S$ parameters of the V/H dual-polarized antenna array. 
TABLE 1: Geometric parameters optimized for the $\mathrm{V} / \mathrm{H}$ dualpolarized antenna.

\begin{tabular}{lc}
\hline Parameter & Value \\
\hline$W_{1}$ & $2.1 \mathrm{~mm}$ \\
$W_{2}$ & $1.7 \mathrm{~mm}$ \\
$W_{3}$ & $8.4 \mathrm{~mm}$ \\
$W_{4}$ & $5 \mathrm{~mm}$ \\
$W_{5}$ & $52.1 \mathrm{~mm}$ \\
$W_{6}$ & $120 \mathrm{~mm}$ \\
$W_{7}$ & $120 \mathrm{~mm}$ \\
$W_{8}$ & $20 \mathrm{~mm}$ \\
$W_{9}$ & $30 \mathrm{~mm}$ \\
$W_{10}$ & $20 \mathrm{~mm}$ \\
$W_{11}$ & $60 \mathrm{~mm}$ \\
$W_{12}$ & $35 \mathrm{~mm}$ \\
$W_{13}$ & $120 \mathrm{~mm}$ \\
$W_{14}$ & $5 \mathrm{~mm}$ \\
$L_{1}$ & $50 \mathrm{~mm}$ \\
$L_{2}$ & $11.5 \mathrm{~mm}$ \\
$L_{3}$ & $8.75 \mathrm{~mm}$ \\
$L_{4}$ & $15.7 \mathrm{~mm}$ \\
$H$ & $43 \mathrm{~mm}$ \\
$t$ & $0.76 \mathrm{~mm}$ \\
$\alpha_{1}$ & $150^{\circ}$ \\
$\alpha_{2}$ & $160^{\circ}$ \\
$\beta_{1}$ & $150^{\circ}$ \\
$\beta_{2}$ & $110^{\circ}$ \\
\hline
\end{tabular}

the broad frequency range is obtained for both VP and HP. The cross-polarization level is lower than $-20 \mathrm{~dB}$. The frontto-back ratios of the antenna array are illustrated in Figure 11, showing the antenna array has a front-to-back ratio higher than $15 \mathrm{~dB}$. The antenna efficiency is also plotted in Figure 11, which is more than $85 \%$ over the frequency range covering $1.7-2.7 \mathrm{GHz}$.

\section{Conclusion}

A broadband $\mathrm{V} / \mathrm{H}$ dual-polarized antenna is proposed for mobile communication base stations. The dual-polarized antenna achieves a HPBW of $65 \pm 8^{\circ}$ for both VP and HP elements, a bandwidth of about $48 \%(1.7-2.75 \mathrm{GHz})$ for RL $>15 \mathrm{~dB}$, and an isolation of $30 \mathrm{~dB}$. The antenna gain is about $9 \mathrm{dBi}$ for both vertical and horizontal polarization. An eightelement $\mathrm{V} / \mathrm{H}$ dual-polarized antenna array is also developed. The antenna array has a bandwidth of $45 \%(1.7-2.7 \mathrm{GHz})$ and an antenna gain of $16 \mathrm{dBi}$ for both VP and HP, which may find potential applications in GSM/UMTS/LTE base stations.

\section{Disclosure}

An earlier version of this paper was presented as a poster at the 11th International Symposium on Antennas, Propagation, and EM Theory (ISAPE 2016).

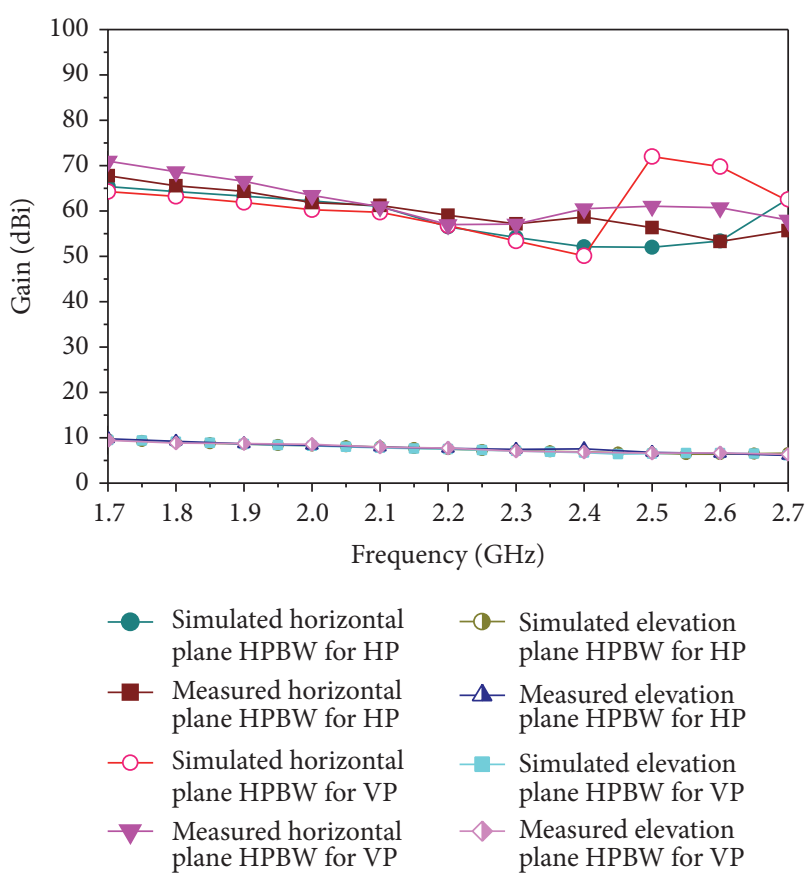

FIGURE 8: HPBWs of the V/H dual-polarized antenna array.

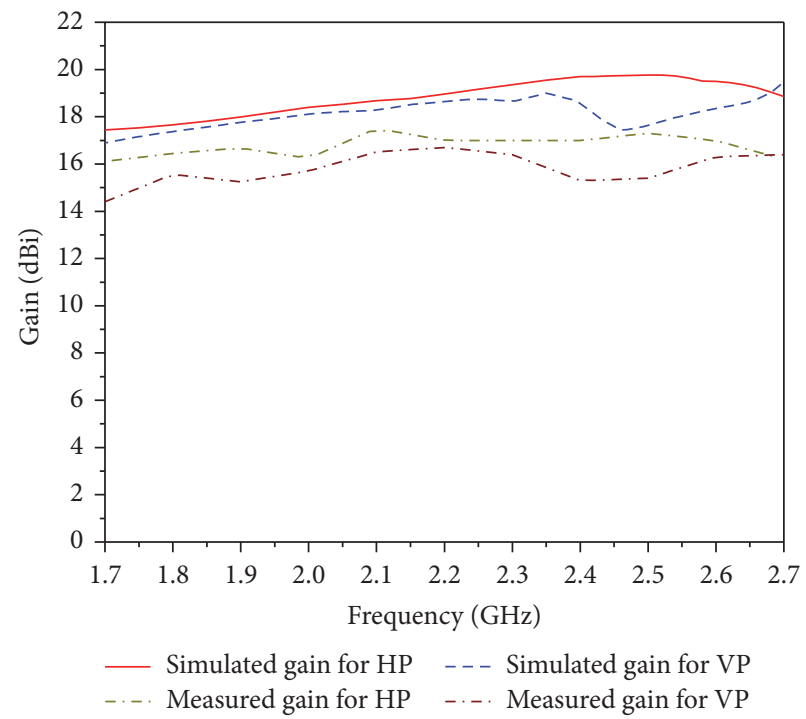

FIGURE 9: Gains of the V/H dual-polarized antenna array.

\section{Conflicts of Interest}

The authors declare that there are no conflicts of interest regarding the publication of this paper.

\section{Acknowledgments}

The authors would like to thank the No. 7 Research Institute of China Electronics Technology Group Corporation, Guangzhou, China. The work was supported in part by the National Science Foundation of China (NSFC) under 

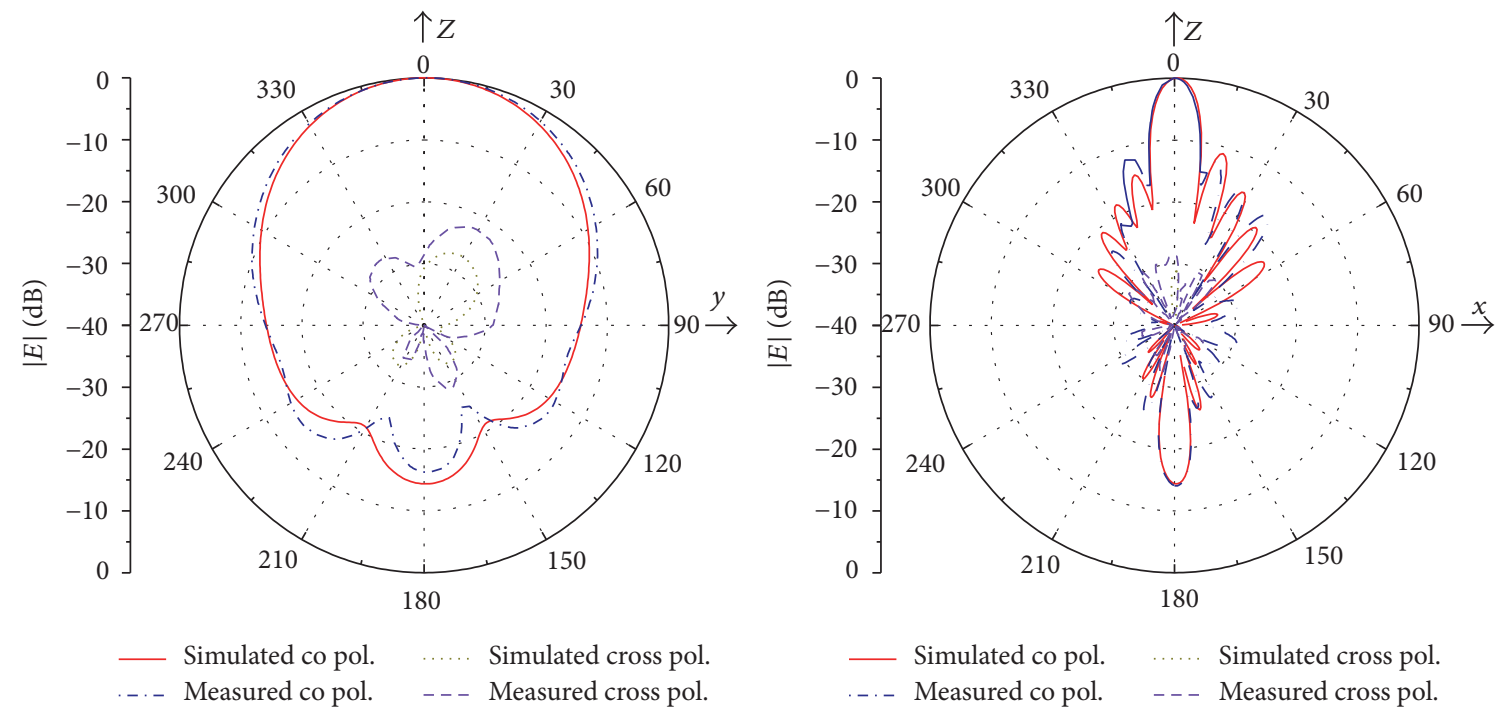

(a)
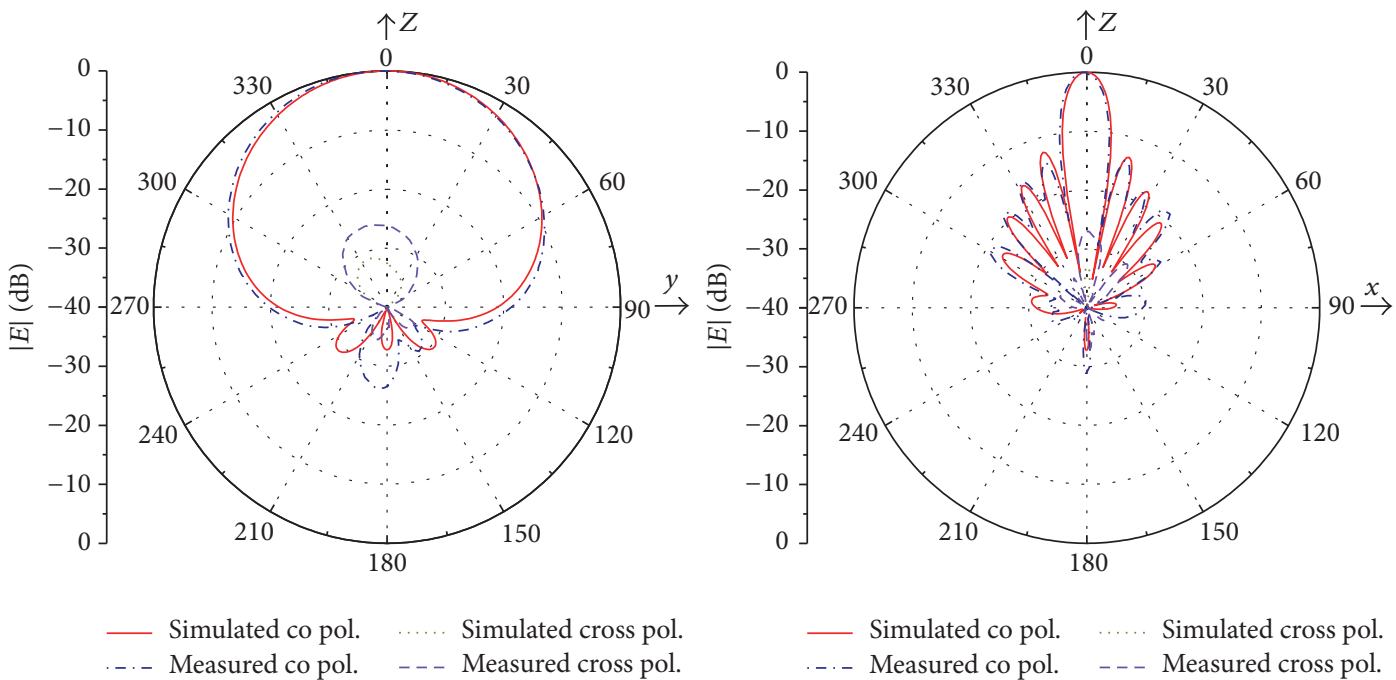

(b)
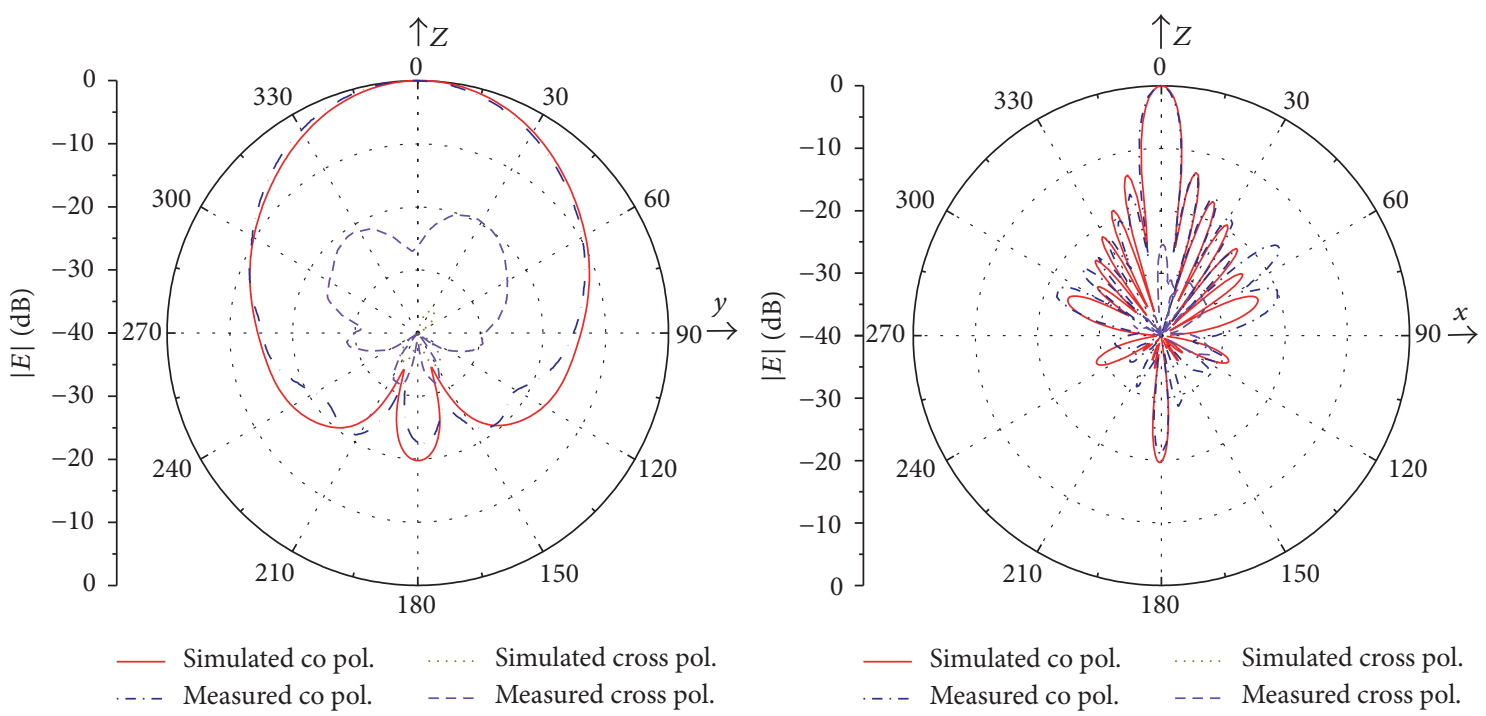

(c)

FIgUre 10: Continued. 

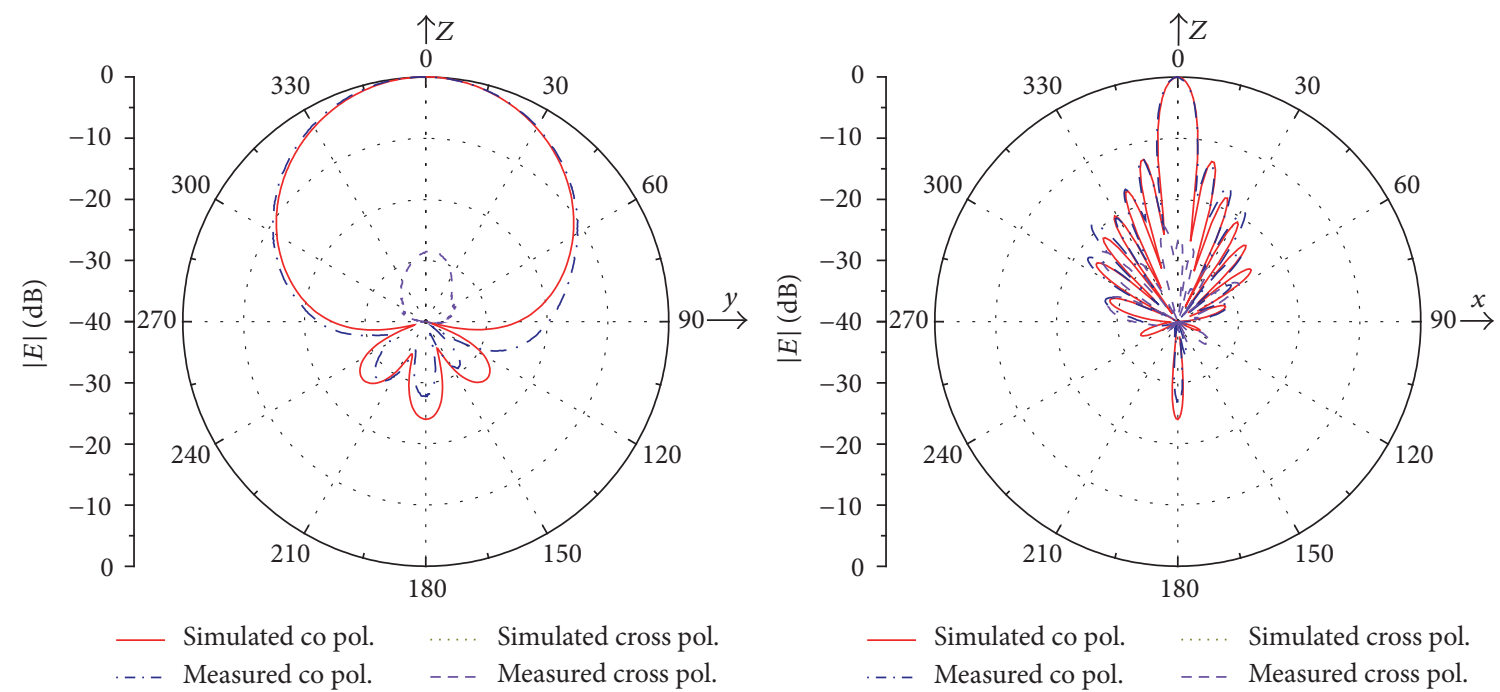

(d)
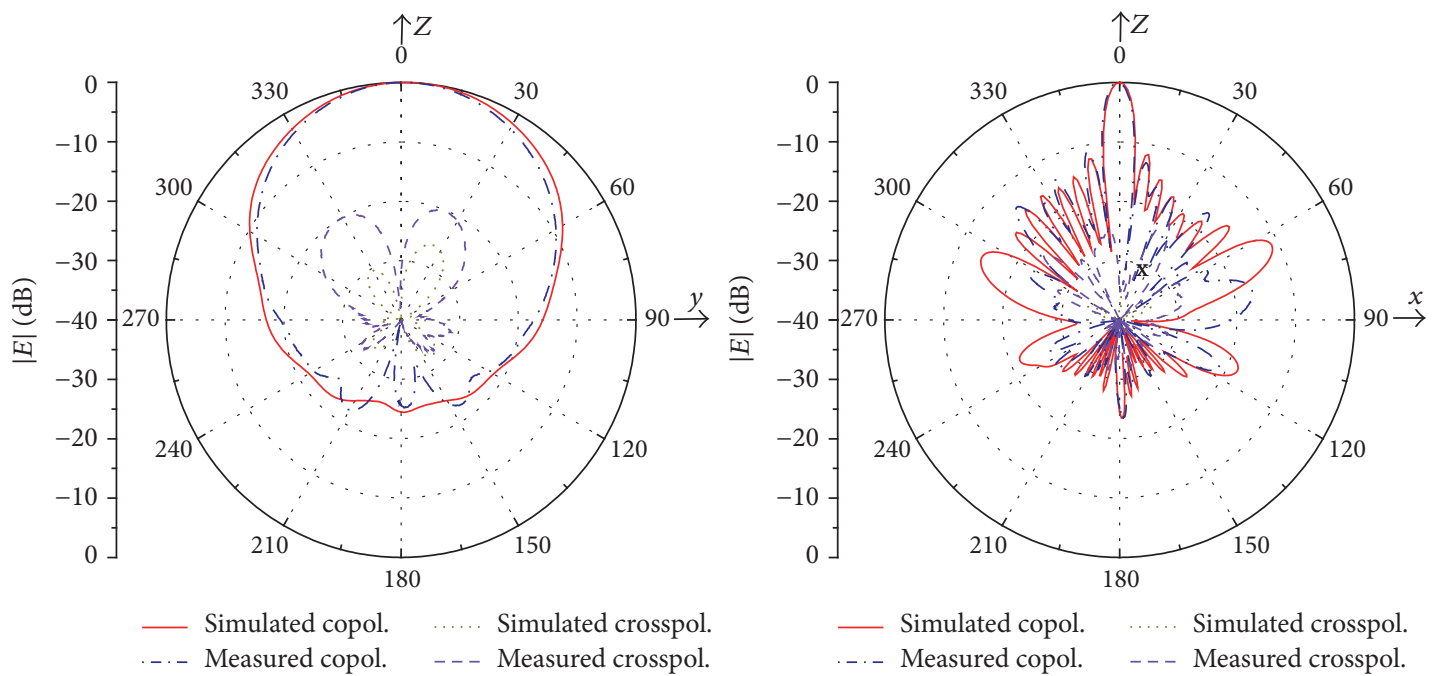

(e)
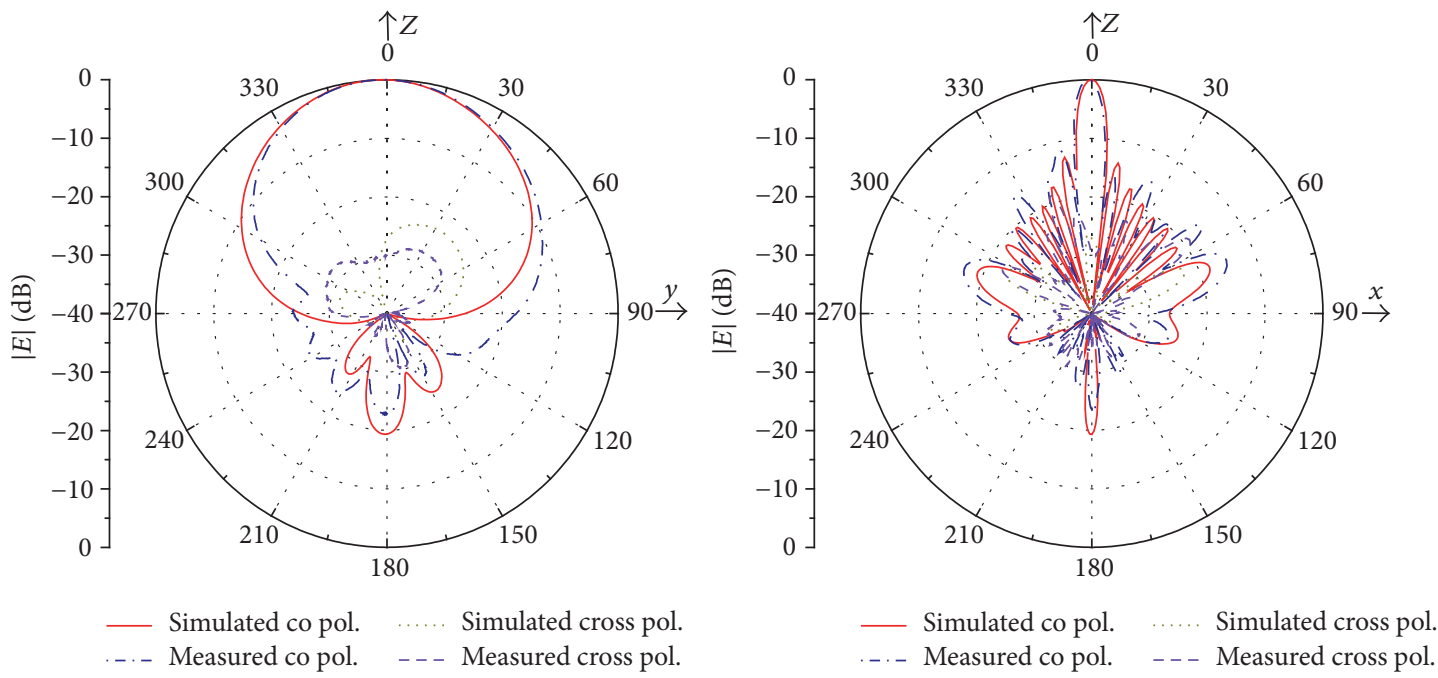

(f)

Figure 10: Radiation patterns of the V/H dual-polarized antenna array: (a) VP at $1.7 \mathrm{GHz}$; (b) HP at $1.7 \mathrm{GHz}$; (c) VP at $2.2 \mathrm{GHz}$; (d) HP at $2.2 \mathrm{GHz}$; (e) VP at $2.7 \mathrm{GHz}$; (f) $\mathrm{HP}$ at $2.7 \mathrm{GHz}$. 


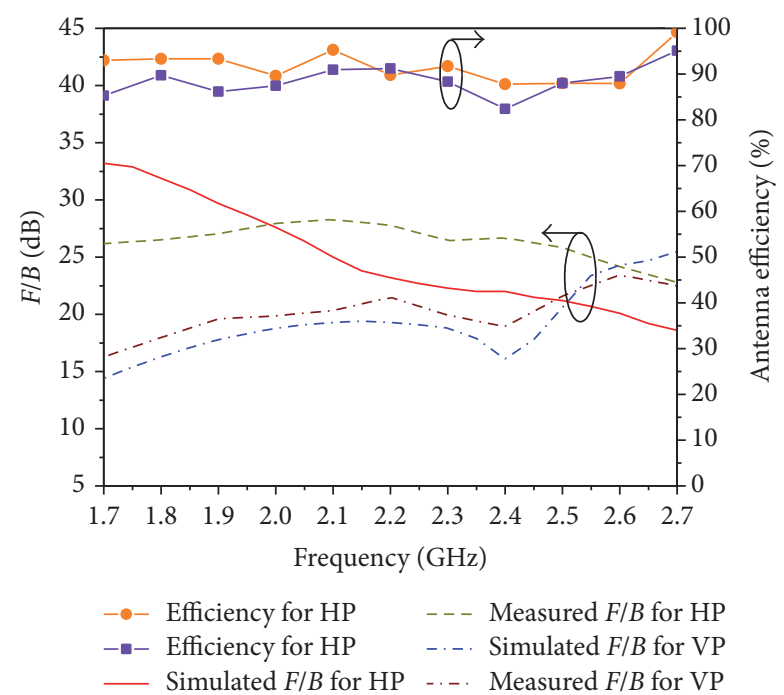

FIGURE 11: Front-to-back ratios and antenna efficiency of the V/H dual-polarized antenna array.

Grant nos. 61501191 and 61372009 and in part by the GDSTC (2014A010103011).

\section{References}

[1] B. Lindmark and M. Nilsson, "On the available diversity gain from different dual-polarized antennas," IEEE Journal on Selected Areas in Communications, vol. 19, no. 2, pp. 287-294, 2001.

[2] J. J. A. Lempiäinen and J. K. Laiho-Steffens, "The performance of polarization diversity schemes at a base station in small/micro cells at $1800 \mathrm{MHz}$," IEEE Transactions on Vehicular Technology, vol. 47, no. 3, pp. 1087-1092, 1998.

[3] A. A. Arowojolu, A. M. D. Turkmani, A. A. Arowojolu, A. M. D. Turkmani, P. A. Jefford, and C. J. Kellett, "An Experimental evaluation of the performance of two-branch space and polarization diversity schemes at $1800 \mathrm{MHz}$,' IEEE Transactions on Vehicular Technology, vol. 44, no. 2, pp. 318-326, 1995.

[4] K.-L. Wong, H.-C. Tung, and T.-W. Chiou, "Broadband dualpolarized aperture-coupled patch antennas with modified $\mathrm{H}$ shaped coupling slots," IEEE Transactions on Antennas and Propagation, vol. 50, no. 2, pp. 188-191, 2002.

[5] S. Gao, L. W. Li, M. S. Leong, and T. S. Yeo, "A broad-band dualpolarized microstrip patch antenna with aperture coupling," IEEE Transactions on Antennas and Propagation, vol. 51, no. 4, pp. 898-900, 2003.

[6] K.-L. Wong and T.-W. Chiou, "Finite ground plane effects on broad-band dual polarized patch antenna properties," IEEE Transactions on Antennas and Propagation, vol. 51, no. 4, pp. 903-904, 2003.

[7] X.-L. Zhao and Q. W. Lin, "Dual-band patch antenna fed by meandering probe for low cross-polarization," International Journal of Antennas and Propagation, vol. 2016, Article ID 5196350, 7 pages, 2016.

[8] Y. Cheng, Y. Li, and W. Lu, "A novel compact dual-polarized antenna," International Journal of Antennas and Propagation, vol. 2016, Article ID 6304356, pp. =-5, 2016.
[9] H. Wong, K.-L. Lau, and K.-M. Luk, "Design of dual-polarized L-probe patch antenna arrays with high isolation," IEEE Transactions on Antennas and Propagation, vol. 52, no. 1, pp. 45-52, 2004.

[10] Y.-X. Guo, K.-W. Khoo, and L. C. Ong, "Wideband dualpolarized patch antenna with broadband baluns," IEEE Transactions on Antennas and Propagation, vol. 55, no. 1, pp. 78-83, 2007.

[11] H.-W. Lai and K.-M. Luk, "Dual polarized patch antenna fed by meandering probes," IEEE Transactions on Antennas and Propagation, vol. 55, no. 9, pp. 2625-2627, 2007.

[12] M. Barba, "A high-isolation, wideband and dual-linear polarization patch antenna," IEEE Transactions on Antennas and Propagation, vol. 56, no. 5, pp. 1472-1476, 2008.

[13] R. Caso, A. Serra, A. Buffi, M. Rodriguez-Pino, P. Nepa, and G. Manara, "Dual-polarised slot-coupled patch antenna excited by a square ring slot," IET Microwaves, Antennas and Propagation, vol. 5, no. 5, pp. 605-610, 2011.

[14] J. Perruisseau-Carrier, T. W. Hee, and P. S. Hall, "Dual-polarized broadband dipole," IEEE Antennas and Wireless Propagation Letters, vol. 2, pp. 310-312, 2003.

[15] G.-X. Zhang, L. Sun, and B.-H. Sun, "A wideband dualpolarized antenna using planar quasi-open-sleeve dipoles for base station applications," International Journal of Antennas and Propagation, vol. 2015, Article ID 164392, 7 pages, 2015.

[16] Y.-H. Huang, Q. Wu, and Q.-Z. Liu, "Broadband dual-polarised antenna with high isolation for wireless communication," Electronics Letters, vol. 45, no. 14, pp. 714-715, 2009.

[17] Z.-Y. Zhang, S. Li, S.-L. Zuo, J.-Y. Zhao, X.-D. Yang, and G. $\mathrm{Fu}$, "Dual-polarized crossed bowtie dipole array for wireless communication applications," International Journal of Antennas and Propagation, vol. 2014, Article ID 349516, 8 pages, 2014.

[18] B. Li, Y.-Z. Yin, W. Hu, Y. Ding, and Y. Zhao, "Wideband dualpolarized patch antenna with low cross polarization and high isolation," IEEE Antennas and Wireless Propagation Letters, vol. 11, pp. 427-430, 2012.

[19] B. Q. Wu and K.-M. Luk, "A broadband dual-polarized magneto-electric dipole antenna with simple feeds," IEEE Antennas and Wireless Propagation Letters, vol. 8, pp. 60-63, 2009.

[20] Y. Cui, R. L. Li, and P. Wang, "A novel broadband planar antenna for 2G/3G/LTE base stations," IEEE Transactions on Antennas and Propagation, vol. 61, no. 5, pp. 2767-2774, 2013. 


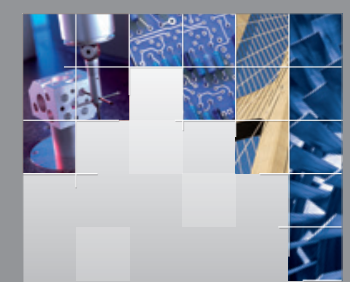

\section{Enfincering}
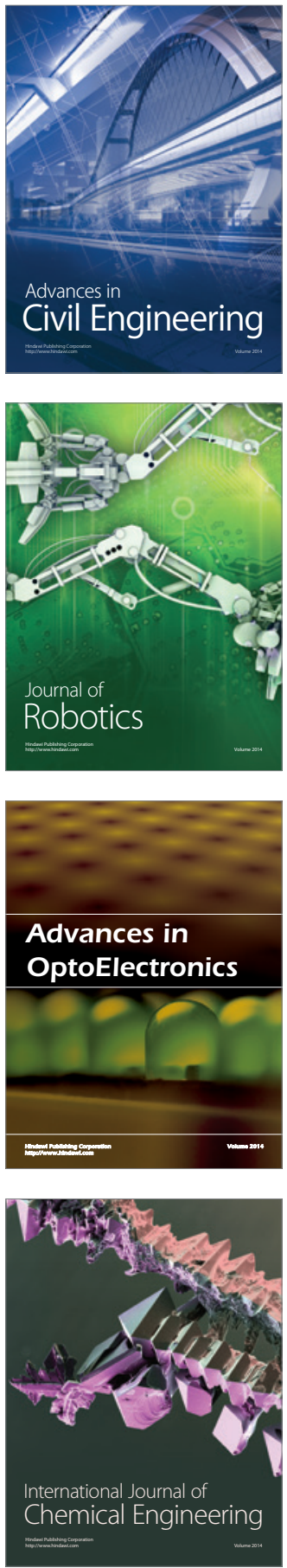

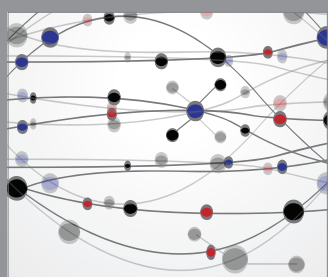

The Scientific World Journal

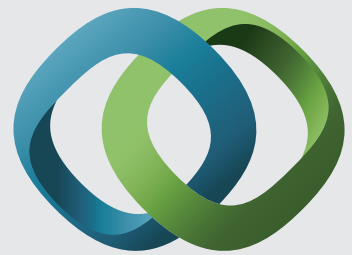

\section{Hindawi}

Submit your manuscripts at

https://www.hindawi.com
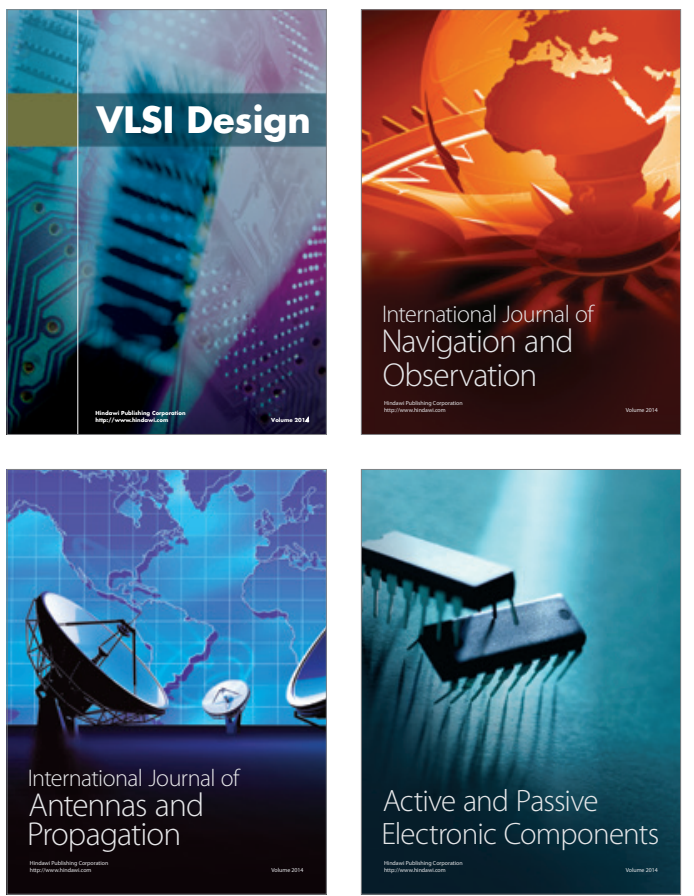
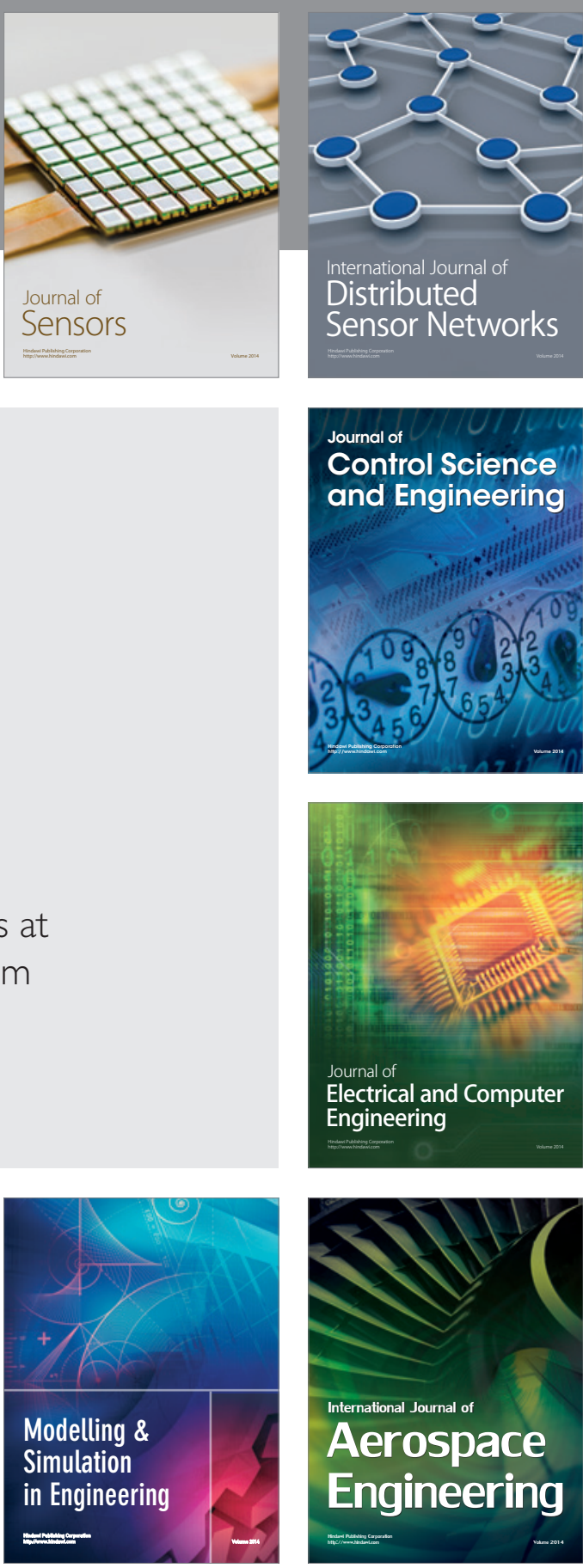

International Journal of

Distributed

Sensor Networks

$-$

Joumal of

Control Science

and Engineering
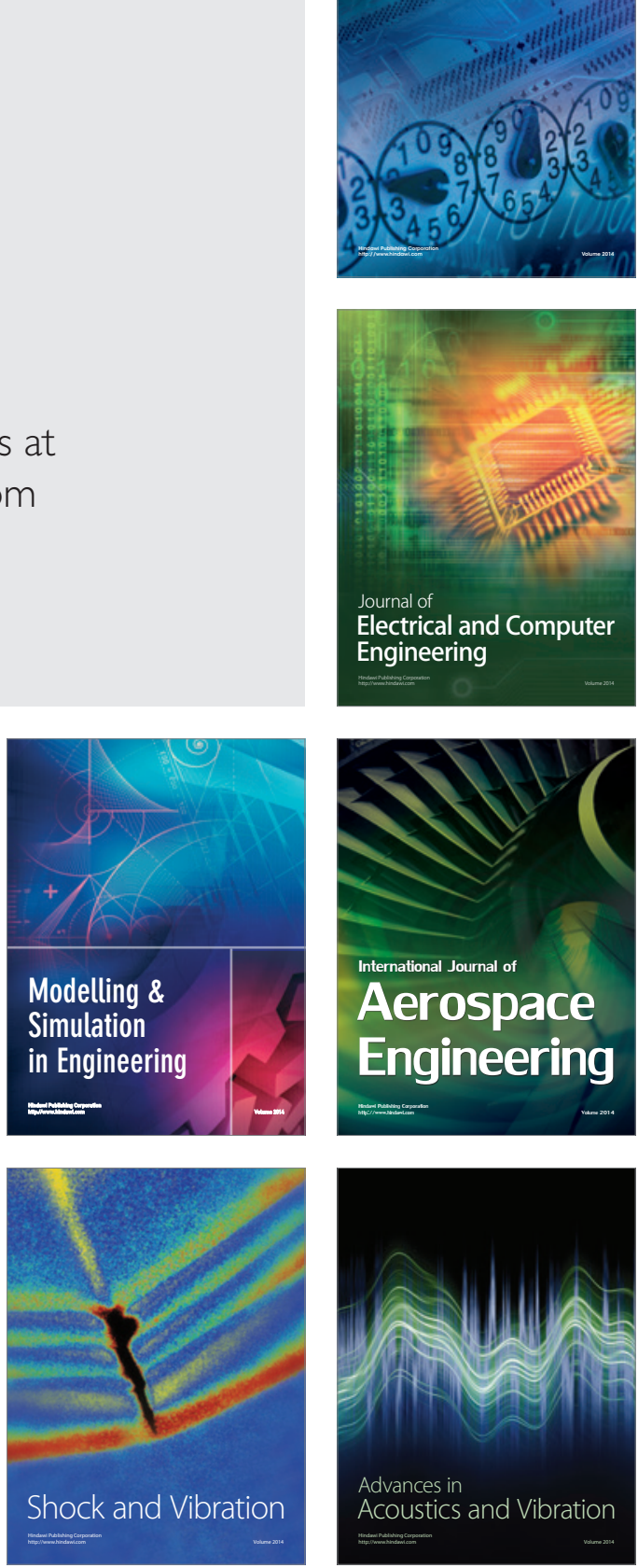